\title{
CDISC SDTM Coronary Artery Dominance Terminology
}

National Cancer Institute

\section{Source}

National Cancer Institute. CDISC SDTM Coronary Artery Dominance Terminology. NCI

Thesaurus. Code C101860.

Terminology associated with the coronary artery dominance codelist of the Clinical Data Interchange Standards Consortium (CDISC) Study Data Tabulation Model (SDT M). 